\title{
Illustration of Cyclic Voltammetric Ascorbic Acid Assessment, with the Anodic Oxidation Peak of the Analyte
}

Aurelia Magdalena Pisoschi*

University of Agronomic Sciences and Veterinary Medicine of Bucharest, Romania

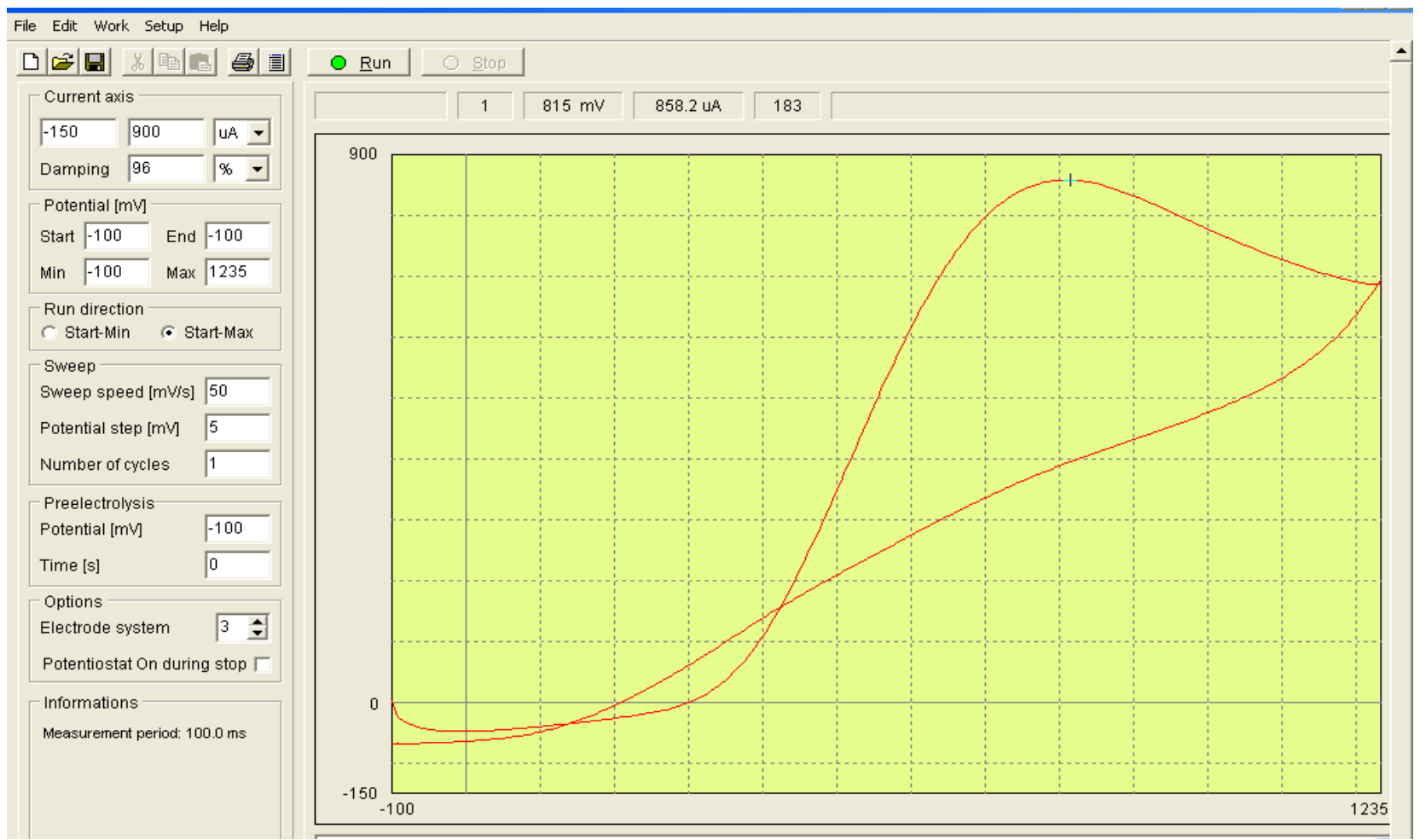

Cyclic voltammogram (current intensity versus potential dependence) recorded with a potentiostat-galvanostat, using a three-electrode electrochemical cell, having a Pt working electrode, a Pt counter-electrode and a calomel reference electrode. The registered analytical response corresponds to a $15 \mathrm{mM}$ ascorbic acid solution, prepared in $0.1 \mathrm{M} \mathrm{KCl}$ as supporting electrolyte. The potential was scanned with a sweep rate of 50 $\mathrm{mV} \mathrm{s}-1$. The intensity of the anodic peak is proportional to the analyte concentration value. The aspect of the voltammogram is consistent with that corresponding to an irreversible redox couple.

*Corresponding author: Aurelia Magdalena Pisoschi, University of Agronomic Sciences and Veterinary Medicine of Bucharest, Romania, Tel: +40 213182266 E-mail: aureliamagdalenapisoschi@yahoo.ro

Received: November 05, 2014; Accepted: November 10, 2014; Published: November 12, 2014

Citation: Pisoschi AM (2014) Illustration of Cyclic Voltammetric Ascorbic Acid Assessment, With the Anodic Oxidation Peak of the Analyte. Biochem Anal Biochem 4: i102. doi: 10.4172/2161-1009.1000i102

Copyright: (C) 2014 Pisoschi AM. This is an open-access article distributed under the terms of the Creative Commons Attribution License, which permits unrestricted use, distribution, and reproduction in any medium, provided the original author and source are credited. 